\title{
A Multiphysics Analysis of Aluminum Welding Flux Composition Optimization Methods
}

\author{
Joseph I. Achebo \\ Department of Production Engineering, University of Benin \\ Nigeria
}

\section{Introduction}

Manufacturing and mass production have been the main factors propelling the drive towards innovation and technological advancement. The principal substance in materials science that has driven this technological drive is metal, and of all the metals, Aluminum is of inestemable value. Welding is the main bane of manufacturing. It is the process used to join two or more pieces of metals permanently together. Aluminum welding, which is the main target of this research, is particularly dependent on the utilization of a suitable welding flux to achieve excellent results. Aluminum is ubiquitous in application and is of great relevance in nearly all fields of technological development and research, invariably, the same applies to its welding flux. Fluxes are invaluable because they facilitate the removal of the Tenacious Aluminum Hydrated Oxide layer $(\mathrm{AlOH})$ which is always found on Aluminum surfaces which have been exposed to atmospheric oxygen. If this Aluminum oxide layer is not removed before or during welding, its chemical constituents, unless reduced to trace amounts, will act as impurities that would significantly compromise the quality of the weld. It is therefore important to understand the characteristics, the chemical composition, morphological personality, and the weld adaptability of Aluminum and its alloys; in general, a multiphysical approach. All geared towards the realization of an optimal flux composition for Aluminum fluxes.

In this chapter, the physics of Aluminum flux composition development process is studied applying several optimization models. To improve on the quality of the welding processes, new ways of developing and optimizing welding fluxes are being investigated with focus on statistical quality control. However, Jackson (1973) was of the opinion that the complex welding technology prevalent in the 1970's demands an understanding of the formulation, manufacture, performance and use of welding fluxes. This statement still holds true even today. He emphasized that the technology leading to proper flux formulation has been little understood. Natalie et al, (1986) said that new engineering requirements demand innovative approaches to the formulation and manufacture of a welding flux. They also observed that the need for higher quality finished metal products, for applications requiring both higher strength and toughness, demands better control of the weld metal composition in the aftermath of any welding using fluxes.

In recent years, mechanical properties such as strength or ductility have been in higher demand in engineering projects, as components are designed to carry even heavier loads. 
Welds of equivalent strength are required to sustain the maintainability and reliability of the continuous use of such materials. Chai \& Eagar (1983) said that the ultimate goal of any weld is the production of a deposit with properties which meet or exceed those of the baseplate.

Each chemical constituent element of a flux has been found by other investigators to influence the quality of the weld, even perhaps increasing the strength of the resulting welds (Achebo \& Ibhadode, 2008). Boniszewski (1979) recognized that there are several formulated flux/coatings compositions. The composition selected depends on its utility. Achebo \& Ibhadode (2009) observed that various manufacturers have produced different flux compositions depending on the weld strengths they intend to achieve; this being the criterion for developing their own unique flux compositions.

An Aluminum welding flux composition is comprised mainly of fluoride and chloride salts. In principle, the real advantage fluoride salts possess is that they are non-hygroscopic, making it quite possible to produce a flux consisting of the fluoride salts only. Chloride salts on the other hand have an affinity for atmospheric oxygen, making them hygroscopic. However, although the fluoride salts are a very vital and effective constituent, the utility of fluoride salts is somewhat inhibited. Firstly, by their relatively high melting point (being higher than $900^{\circ} \mathrm{C}$ ), and secondly, by their diminished ability to completely dissolve the Aluminum oxide layer on their own. The interaction of the fluoride salts with atmospheric oxygen and moisture found within the weld environment (in the form of vapour), could cause the evolution of harmful gases such as Aluminum Fluoride (AlF), and Hydrogen Fluoride (HF). These gases are highly carcinogenic. This is the main reason fluoride salts' inclusion as one of the flux constituent elements, is in perpetually smaller proportion to other additives. Jackson (1973) wrote that Calcium Fluoride $\left(\mathrm{CaF}_{2}\right)$ for instance would usually make up only about $5 \%$ to $7 \%$ of the composition. However, according to him, this proportion could be in even larger quantities for special purpose fluxes, servicing a niche market. Utigard et al (1998) said that fluoride salts could be up to $20 \%$ by weight. The application and use of such fluoride heavy fluxes must however to be balanced against the health risks involved.

Chloride salts are a virtually safe constituent elements and could be applied generously. The majority of the chloride salts of alkali and alkali earth elements have a melting point lower than $800^{\circ} \mathrm{C}$ and consequently they melt in the stage of formation of the droplet, ensuring sufficient shielding of the slag. The chlorides of Potassium (K), Sodium (Na), Lithium (Li), and Calcium (Ca), are hygroscopic. Chlorides salts exhibit the same property as fluorides but to a much lesser extent being in the same active element group. Their stability in dissolving $\mathrm{AlOH}$ can be predicted from the simplistic concept of electro-negativity series theory (Utigard et al, 1998). The reason fluorides and chlorides of potassium, sodium and calcium are used to dissolve the $\mathrm{AIOH}$ is explained by the Gibbs Energy of Formation, as well as the Electro-Negativity Series Theory. Utigard et al, (1998) suggest in their work that as the stability of the compound increases with an increasing negative value of the Gibbs energy formation, the thermodynamic stability decreases, in the order of, fluorides > chlorides $>$ oxides $>$ suffides $>$ phosphates $>$ nitrates $>$ carbonates.

This explains why a compound containing oxides can only be removed / or dissolved by fluoride and chloride compounds. From the Gibbs energy of formation, fluoride is more effective than chloride in removing oxides, i.e. fluorides are more stable than the corresponding elements; chloride $>$ oxide $>$ sulfide (Utigard et al, 1998).

In the electro-negativity series, the metal elements are in the order: $\mathrm{Li}, \mathrm{K}, \mathrm{Na}, \mathrm{Ca}, \mathrm{Mg}, \mathrm{Al}, \mathrm{Zn}$, $\mathrm{Fe}, \mathrm{Pb}, \mathrm{H}, \mathrm{Cu}, \mathrm{Hg}, \mathrm{Ag}, \mathrm{Au}$. The more reactive metals are lithium, potassium, sodium, 
calcium and magnesium. The reactive metals are Aluminum, Zinc, Iron and the less reactive metals are lead, copper, mercury, silver, and gold (Holderness \& Lambert, 1982). The compounds within these three groups described above (i.e, more reactive metals, reactive metals and less reactive metals) can be substituted for one another, that is, in a particular group any element can be substituted for the other, if their individual effects, when used as flux material, are not significantly different from each other. Since these elements are surface active elements within the same group, they are likely to achieve vastly similar results or effects.

As a general rule, the higher the difference in electronegativity between any two elements, the greater the bond strength and stability of any compound made up of these two elements. This means that any metal higher up in the series will displace from its salts any metal below it. The greater the gap separating the metals in the series, the more readily will the displacement take place (Holderness \& Lambert, 1982).

Therefore, only $\mathrm{Li}, \mathrm{K}, \mathrm{Na}, \mathrm{Ca}$ and $\mathrm{Mg}$ can displace $\mathrm{Al}$, but since $\mathrm{K}, \mathrm{Na}, \mathrm{Ca}$ and $\mathrm{Mg}$ are the more reactive metals, they are the elements that effectively displace Aluminum considering the Gibbs energy of formation. Fluoride and chloride compounds of $\mathrm{K}, \mathrm{Na}$, $\mathrm{Ca}$ and $\mathrm{Mg}$ can effectively dissolve AIOH.

From the series, it is shown that all metals higher in the series than hydrogen displace it. Therefore, the metals high up in the series being $\mathrm{K}, \mathrm{Na}$, $\mathrm{Ca}$ and $\mathrm{Mg}$ would most effectively displace hydrogen from the molten weld pool. In general the higher metals in the series oxidize readily. They float to the top to form slag to protect the weld bead from contact with the environment (thus preventing oxidation and re-oxidation). Utigard et al (1998) were of the opinion that although chloride salts strip Aluminum of its oxide and assists in the coalescence of Aluminum, the interfacial tension between Aluminum and chloride based melts does not change with the addition of chlorides or with the variation in the composition of chloride salts. On the other hand, the addition of fluorides decreases the interfacial tension to various extents due to the absorption of $\mathrm{Na}$ and $\mathrm{K}$ at the interface. Further research carried out explains that the combination with chloride salt reduces its melting point (eutectic) but the addition of fluoride salt further reduces the melting temperature (ternary eutectic). A low melting point is important since it improves the fluidity of the flux and forms a thin layer on the melt surface. Lincoln Electric Foundation wrote that low melting point components in the molten weld metal are forced to the center of the joint during solidification since they are the last to solidify.

In this study, the multiphysical examination explains the displacement of a constituent element by a superior or more active element. The mechanical property of ductility and strength is here applied as a standard to determine flux compositions. Optimization methods such as Hadamard Matrix design and Taguchi experimental design methods alongside with the Expert evaluation method were also used in this study to develop optimum flux compositions. The efficiencies of these methods were compared and analyzed.

\section{The Hadamard matrix design for four variables}

The two level multivariate factorial design generated from the Hadamard matrices, was formulated by Jacques Hadamard, a French mathematician, in 1893. He has shown the applicability of these matrices to most two level experimental designs; where a two level experimental design is a design that operates in a range of values within a low level and a high level. Two level multivariate resolution IV Hadamard matrix design is a two level, four 
variable experimental design; each of the four variables has a high level and a low level (Diamond, 1989). All designs (regardless of numbers of compositions or variables), where all the main effects of the compositions and groups of interactions between the variables that constitute the flux compositions are known and computed, can be estimated. The model as illustrated hereunder is used to obtain an optimum flux composition amongst a wide range of existing flux compositions.

The Aluminum welding flux composition used for this study is as expressed in Table 1

\begin{tabular}{|ll|l|}
\hline $\begin{array}{l}\text { Flux Material } \\
\text { Designation }\end{array}$ & $\begin{array}{l}\text { Constituent Element } \\
\text { (\% by weight) }\end{array}$ \\
\hline A $\quad \mathrm{LiCl}$ & $25-30$ at most 35 \\
\hline $\mathrm{B}$ & $\mathrm{NaCl}$ & $30-45$ \\
\hline $\mathrm{C}$ & $\mathrm{KCl}$ & $30-40$ \\
\hline $\mathrm{D}$ & $\mathrm{CaF}_{2}$ & $5-10$ \\
\hline
\end{tabular}

Table 1. Aluminum Welding Flux Chemical Composition

The Hadamard matrix design layout for four variables is shown in Table 2

\begin{tabular}{|c|c|c|c|c|c|c|c|c|c|}
\hline Flux No & 0 & $\begin{array}{l}\mathrm{A} \\
1\end{array}$ & $\begin{array}{l}\text { B } \\
2\end{array}$ & $\begin{array}{l}C \\
3\end{array}$ & $\begin{array}{l}\mathrm{CD} \\
-\mathrm{AB} \\
4\end{array}$ & $\begin{array}{l}\mathrm{AD} \\
-\mathrm{BC} \\
5\end{array}$ & $\begin{array}{l}\mathrm{D} \\
\mathrm{ABC} \\
6\end{array}$ & $\begin{array}{l}\mathrm{BD} \\
-\mathrm{AC} \\
7\end{array}$ & $\begin{array}{l}\text { Treatment } \\
\text { comninations }\end{array}$ \\
\hline 1 & + & + & - & - & + & - & + & + & $\mathrm{ad}$ \\
\hline 2 & + & + & + & - & - & + & - & + & $a b$ \\
\hline 3 & + & + & + & + & - & - & + & - & abcd \\
\hline 4 & + & - & + & + & + & - & - & + & bc \\
\hline 5 & + & + & - & + & + & + & - & - & ac \\
\hline 6 & + & - & + & - & + & + & + & - & $\mathrm{bd}$ \\
\hline 7 & + & - & - & + & - & + & + & + & $\mathrm{cd}$ \\
\hline 8 & + & - & - & - & - & - & - & - & (1) \\
\hline
\end{tabular}

Table 2. Hadamard Matrix Design For Four Variables (Diamond, 1989)

The main flux variables A, B, C and D were extracted from Table 2 and the flux composition ranges in Table 1 were used to fill the matrices of the extracted variables noting that $(+)$ signifies a high value of the flux composition ranges and (-) signifies a low level of the composition ranges; the fourth variable $\mathrm{D}$ being considered first in the formulation process. The other variables $\mathrm{A}, \mathrm{B}$ and $\mathrm{C}$ are filled in the first three columns and the column reserved for the D variable is left blank. Bearing in mind that the condition of this formulation process states that each composition or trial must add up to $100 \%$ by weight, to make a complete composition. Then variables $\mathrm{A}, \mathrm{B}$ and $\mathrm{C}$ are added up and the remaining value to sum it up to $100 \%$ by weight is entered on the D column if that value falls within the range or limits set for variable $\mathrm{D}$ as specified in Table 1 . However, if the value is above or below the range, it would be skipped (Diamond, 1989) as shown in Tables 3 - 5 


\begin{tabular}{|l|l|l|l|l|l|}
\hline Flux No & A & B & C & D & \\
\hline 1 & 30 & 30 & 30 & 10 & $(1)$ \\
\hline 2 & 30 & 45 & 30 & - & \\
\hline 3 & 30 & 45 & 40 & - & \\
\hline 4 & 25 & 45 & 40 & - & \\
\hline 5 & 30 & 30 & 40 & - & \\
\hline 6 & 25 & 45 & 30 & - & \\
\hline 7 & 25 & 30 & 40 & 5 & $(2)$ \\
\hline 8 & 25 & 30 & 30 & - & \\
\hline
\end{tabular}

Table 3. Step 1: Considering Variable D, $\mathrm{CaF}_{2}(5-10 \%)$

\begin{tabular}{|l|l|l|l|l|l|}
\hline Flux No & A & B & C & D & \\
\hline 1 & 30 & 30 & 30 & 10 & $(1)$ \\
\hline 2 & 30 & 45 & - & 5 & \\
\hline 3 & 30 & 45 & - & 10 & \\
\hline 4 & 25 & 45 & - & 5 & \\
\hline 5 & 30 & 30 & 35 & 5 & $(3)$ \\
\hline 6 & 25 & 45 & - & 10 & \\
\hline 7 & 25 & 30 & 35 & 10 & $(4)$ \\
\hline 8 & 25 & 30 & 40 & 5 & $(2)$ \\
\hline
\end{tabular}

Table 4. Step 2: Considering Variable C, $\mathrm{KCl}(30-40 \%)$

\begin{tabular}{|l|l|l|l|l|l|}
\hline Flux No & A & B & C & D & \\
\hline 1 & 30 & 30 & 30 & 10 & $(1)$ \\
\hline 2 & 30 & 35 & 30 & 5 & $(5)$ \\
\hline 3 & 30 & - & 40 & 10 & \\
\hline 4 & 25 & 30 & 40 & 5 & $(2)$ \\
\hline 5 & 30 & - & 40 & 5 & \\
\hline 6 & 25 & 35 & 30 & 10 & $(6)$ \\
\hline 7 & 25 & - & 40 & 10 & \\
\hline 8 & 25 & 40 & 30 & 5 & $(7)$ \\
\hline
\end{tabular}

Table 5. Step 3: Considering Variable B, $\mathrm{NaCl}(30-45 \%)$ 


\begin{tabular}{|l|l|l|l|l|l|}
\hline Flux No & A & B & C & D & \\
\hline 1 & 30 & 30 & 30 & 10 & $(1)$ \\
\hline 2 & - & 45 & 30 & 5 & \\
\hline 3 & - & 45 & 40 & 10 & \\
\hline 4 & - & 45 & 40 & 5 & \\
\hline 5 & 25 & 30 & 40 & 5 & $(2)$ \\
\hline 6 & - & 45 & 30 & 10 & \\
\hline 7 & - & 30 & 40 & 10 & \\
\hline 8 & 35 & 30 & 30 & 5 & $(8)$ \\
\hline
\end{tabular}

Table 6. Step 4: Considering Variable A, $\mathrm{L}_{\mathrm{i}} \mathrm{Cl}(25$ - 30\%)

The summary of the eight (8) newly formulated welding flux chemical compositions based on the given flux composition ranges in Table 1 and extracted from the procedures conducted in Tables $3-6$ is shown in Table 7.

\begin{tabular}{|l|l|l|l|l|}
\hline Flux No. & $\mathrm{LiCl}$ & $\mathrm{NaCl}$ & $\mathrm{KCl}$ & $\mathrm{CaF}_{2}$ \\
\hline 1 & 30 & 30 & 30 & 10 \\
\hline 2 & 25 & 30 & 40 & 5 \\
\hline 3 & 30 & 30 & 35 & 5 \\
\hline 4 & 25 & 30 & 35 & 10 \\
\hline 5 & 30 & 35 & 30 & 5 \\
\hline 6 & 25 & 35 & 30 & 10 \\
\hline 7 & 25 & 40 & 30 & 5 \\
\hline 8 & 35 & 30 & 30 & 5 \\
\hline
\end{tabular}

Table 7. Eight newly formulated chemical compositions (\% by wt)

\begin{tabular}{|l|l|}
\hline $\begin{array}{l}\text { Flux } \\
\text { No. }\end{array}$ & $\begin{array}{l}\text { UTS } \\
\text { MPa }\end{array}$ \\
\hline 1 & 293 \\
\hline 2 & 302 \\
\hline 3 & 262 \\
\hline 4 & 296 \\
\hline 5 & 303 \\
\hline 6 & 296 \\
\hline 7 & 254 \\
\hline 8 & 243 \\
\hline
\end{tabular}

Table 8. The average UTS Results of the Weld Metals made by the Eight Newly formulated fluxes. 
Each treatment combination (i.e. flux composition) was used to make five weld deposits which were machined into the standard dimension required to make the samples needed to conduct tensile tests in accordance with the Federal Test Method Standard No. 151 Metals Test methods. The average ultimate tensile strength (UTS) results were recorded as shown in Table 8.

The main variables defining the constituent elements of the flux material have been obtained. Here since the UTS has been determined for each flux combination. The next step is to determine the effect of these main variables on weld strength.

\begin{tabular}{|l|l|l|l|l|}
\hline Flux No. & A & B & C & D \\
\hline 1 & +293 & -293 & -293 & +293 \\
\hline 2 & +302 & +302 & -302 & -302 \\
\hline 3 & +262 & +262 & +262 & +262 \\
\hline 4 & -296 & +296 & +296 & -296 \\
\hline 5 & +303 & -303 & +303 & -303 \\
\hline 6 & -296 & +296 & -296 & +296 \\
\hline 7 & -254 & -254 & +254 & +254 \\
\hline 8 & -243 & -243 & -243 & -243 \\
\hline$\sum X_{\text {high }}-\sum X_{\text {low }}$ & 71 & 63 & -19 & -39 \\
\hline
\end{tabular}

Table 9. Effects of flux composition on weld strength (UTS)

The mean effects of the main variables are determined as follows:

$$
\begin{gathered}
\overline{\mathrm{X}} \mathrm{A}_{\text {high }}-\overline{\mathrm{X}} \mathrm{A}_{\text {low }}=\frac{71}{4}=17.75 \\
\overline{\mathrm{X}} \mathrm{B}_{\text {high }}-\overline{\mathrm{X}} \mathrm{B}_{\text {low }}=\frac{63}{4}=15.75 \\
\overline{\mathrm{X}} \mathrm{C}_{\text {high }}-\overline{\mathrm{X}} \mathrm{C}_{\text {low }}=\frac{-19}{4}=-4.75 \\
\overline{\mathrm{X}} \mathrm{D}_{\text {high }}-\overline{\mathrm{X}} \mathrm{D}_{\text {low }}=\frac{-39}{4}=-9.75
\end{gathered}
$$

Having obtained the mean above, the estimates of the variances of the contrast are estimated as is expressed in Table 10

The variances of contrast 5, 6 and 7 are estimated as follows:

$$
S_{i}^{2}=\frac{\left[\sum(\text { Column sign })(\text { Test result })\right]^{2}}{T}
$$

Where $\mathrm{T}$ is the number of flux compositions of the experiments $=8$ and $\mathrm{i}$ represents the contrast numbers (in this case $\mathrm{i}=5,6$ and 7). Applying Eq (1). 


\begin{tabular}{|l|l|l|l|}
\hline $\begin{array}{l}\text { Flux } \\
\text { No }\end{array}$ & $\begin{array}{l}\text { Contrast 5 } \\
\text { CD }- \text { AB }\end{array}$ & $\begin{array}{l}\text { Contrast 6 } \\
\text { AD - BC }\end{array}$ & $\begin{array}{l}\text { Contrast 7 } \\
\text { BD - AC }\end{array}$ \\
\hline 1 & +293 & -293 & +293 \\
\hline 2 & -302 & +302 & +302 \\
\hline 3 & -262 & -262 & -262 \\
\hline 4 & +296 & -296 & +296 \\
\hline 5 & +303 & +303 & -303 \\
\hline 6 & +296 & +296 & -296 \\
\hline 7 & -254 & +254 & +254 \\
\hline 8 & -243 & -243 & -243 \\
\hline$\sum\left(X_{\text {high }}-X_{\text {low }}\right)$ & 127 & 61 & 41 \\
\hline
\end{tabular}

Table 10. Estimates of the variance of the contrasts

$$
\begin{gathered}
S_{5}^{2}=\frac{(127)^{2}}{8}=2016.125 \\
S_{6}^{2}=\frac{(61)^{2}}{8}=465.125 \\
S_{7}^{2}=\frac{(41)^{2}}{8}=210.125
\end{gathered}
$$

The average of variances of contrast 5, 6, and 7 are estimated from the equation

$S_{\text {avg }}^{2}=\frac{\sum_{j}^{i} S_{i}^{2}}{j}$ with $\mathrm{j}$ degrees of freedom

$\mathrm{j}=\mathrm{N}-1$ degrees of freedom. $\mathrm{N}$ is the number of flux elements $=4$.

$$
S_{\text {avg }}^{2}=\frac{2016.125+465.125+210.125}{3}
$$

$=897.125$

Whereas, the standard deviation is the square root of the average variance of contrasts 5, 6 and 7. This is obtained as is expressed as follows

$$
S=\sqrt{897.125}=29.95
$$

\subsection{Test criterion determination}

At chosen values of 3 degrees of freedom, $\phi$; where $a=0.05$ at $95 \%$ confidence level, $t_{\beta}=2.35\left(t_{\beta}\right.$ is obtained from probability points of $\mathrm{t}$-distribution single sided table when $\sigma^{2}$ is unknown). Since $\mathrm{N}_{\text {high }}=\mathrm{N}_{\text {low }}=4$ and $\mathrm{S}=29.95$, substituting values into the selection criterion, as expressed hereunder, is a standardized equation for selecting the chemical composition constituent elements. 


$$
\left|\bar{X}_{\text {high }}-\bar{X}_{\text {low }}\right|^{*}=t_{\beta} S \sqrt{\frac{1}{N_{\text {high }}}+\frac{1}{N_{\text {low }}}}
$$

$=2.35(29.95) \sqrt{\frac{1}{4}+\frac{1}{4}}$

$=2.35(29.95) \times 0.7071=49.77$

\subsection{Conditions for making decision}

A low value is desirable if the mean effect is positive, the low level $(\mu$ low) is better. If the mean effect is negative, the high level ( $\mu$ high) is better, that is,

If $\left(\bar{X}_{\text {high }}-\bar{X}_{\text {low }}\right)$ is negative and $\left|\bar{X}_{\text {high }}-\bar{X}_{\text {low }}\right|>\left|\bar{X}_{\text {high }}-\bar{X}_{\text {low }}\right|^{*}$ accept that $\mu$ high is better than $\mu$ low

If $\left(\bar{X}_{\text {high }}-\bar{X}_{\text {low }}\right)$ is positive and greater than $\left|\bar{X}_{\text {high }}-\bar{X}_{\text {low }}\right|^{*}$, accept that $\mu$ low is better than $\mu$ high

* signifies the standard selection criterion

\subsection{Selection test}

The selection test is done by comparing the average mean effect of the main variables determined from Table 9 with the mean effect of the standard selection $\left(^{*}\right)$ for the variables under study as it relates to variables A, B, C and D below

$$
\left(\left|\bar{X} A_{\text {high }}-\bar{X} A_{\text {low }}\right|=17.75\right)<\left(\left|\bar{X}_{\text {high }}-\bar{X}_{\text {low }}\right|^{*}=49.77\right)
$$

From the above, and subject to the conditions for making decision criteria, $\mu A_{\text {high }}$ is better than $\mu A_{\text {low }}$. Therefore high $\mathrm{A}$ is acceptable.

$$
\left(\left|\bar{X} B_{\text {high }}-\bar{X} B_{\text {low }}\right|=15.75\right)<\left(\left|\bar{X}_{\text {high }}-\bar{X}_{\text {low }}\right|^{*}=49.77\right)
$$

From the above and subject to the conditions for making decision criteria, $\mu B_{\text {high }}$ is better than $\mu B_{\text {low }}$. Therefore high $\mathrm{B}$ is acceptable.

$$
\left(\left|\bar{X} C_{\text {high }}-\bar{X} C_{\text {low }}\right|=-4.75\right)<\left(\left|\bar{X}_{\text {high }}-\bar{X}_{\text {low }}\right|^{*}=49.77\right)
$$

From the above and subject to the conditions for making decision criteria, $\mu C_{\text {low }}$ is better than $\mu C_{\text {high }}$. Therefore low $\mathrm{C}$ is acceptable

$$
\left(\left|\bar{X} D_{\text {high }}-\bar{X} D_{\text {low }}\right|=-9.75\right)<\left(\left|\bar{X}_{\text {high }}-\bar{X}_{\text {low }}\right|^{*}=49.77\right)
$$

From the above and subject to the conditions for making decision criteria, $\mu D_{\text {low }}$ is better than $\mu D_{\text {high }}$. Therefore low $\mathrm{D}$ is acceptable

\subsection{Decision}

From the conditions for making the decision described above and considering the selection test as is also stated above, it is deduced that the best combination of the variables 
statistically derived is as follows: high $\mathrm{A}$, high $\mathrm{B}$, low $\mathrm{C}$ and low $\mathrm{D}$, which is $\mathrm{A}=30 \%$, $B=45 \%, C=30 \%$ and $D=5 \%$. The sum of these percentages by weight adds up to $110 \%$. However, being that percentages need to be rounded up to portions per hundred, a novel approach has to be introduced for this combination to add up to $100 \%$ by weight.

This novel approach is stated thus: in the case where certain elements that constitute a flux composition possess a high percent by weight or proportion, the average value should be determined. Values below that average value should be considered to be of the lower range, and those above it, should be considered to be of the higher range, within the initially specified range of values as reflected in Table 1 . The iteration is done in such a way that the $100 \%$ by weight threshold value is not exceeded. This approach was adopted to arrive at the best or optimum combination of $\mathrm{A}=27.5 \%, \mathrm{~B}=37.5 \%, \mathrm{C}=30 \%$ and $\mathrm{D}=5 \%(27.5 \% \mathrm{LiCl}$, $37.5 \% \mathrm{NaCl}, 30 \% \mathrm{KCl}$ and $5 \% \mathrm{CaF}_{2}$ ). This combination was used to conduct a welding process and the weld deposits were prepared to suit the standard tensile test specimen which were subjected to tensile test and an average UTS of $316 \mathrm{MPa}$ was obtained. This test confirms the reliability of the applied model.

\section{Taguchi method}

The Taguchi methods are statistical methods developed by Genichi Taguchi to improve the quality of manufactured goods. Dr. Genichi Taguchi was born in Japan in 1924, and has displayed a keen interest in quality management in general. He has developed and promoted a philosophy and methodology for continuous quality improvement in products and processes. His methods have also been successfully applied to engineering experimentation. The Taguchi method can show how Statistical Design of Experiments (SDOE or DOE) can help industrial engineers design and manufacture products that are both of high quality and low cost (Antony \& Antony, 2001). According to Antony \& Antony (2001), DOE is a powerful statistical technique for determining the optimal factor settings of a process and thereby achieving improved process performance, reduced process variability and improved manufacturability of products and processes. Taguchi understood that excessive variation lay at the root of poor manufactured quality and that reacting to individual items inside and outside specification was counterproductive. Taguchi realized that the best opportunity to eliminate variation is during the design of a product and its manufacturing process. Esme (2009) wrote that the Taguchi method uses a special design of orthogonal arrays to study the entire process parameters with only a small number of experiments. Using an orthogonal array to design the experiment could help the designers to study the influence of multiple controllable factors on the average of quality characteristics and the variations, in a fast and economic way, while using a signal - to noise ratio to analyze the experimental data that could help the designers of the product or the manufacturer to easily find out the optimal parametric combinations. A loss function is defined to calculate the deviation between the experimental value and the desired value. The loss function is further transformed into signal - to - noise $(\mathrm{S} / \mathrm{N})$ ratio. The statistical analysis of variance (ANOVA) is performed to see which process parameters are statistically significant. The Taguchi method is illustrated herein-under to predict the optimum combination of Aluminum welding flux.

From the layout in Table 1 , an $\mathrm{L}_{8}\left(2^{4}\right)$ orthogonal array which has 7 degrees of freedom was applied. In this case eight experimental procedures are conducted when using $\mathrm{L}_{8}$ orthogonal array. The corresponding experimental layout is as expressed in Table 11. 


\begin{tabular}{|l|l|l|l|l|}
\hline \multirow{2}{*}{$\begin{array}{l}\text { Experiment } \\
\text { Number }\end{array}$} & \multicolumn{4}{|l|}{ Flux constituent element levels } \\
\cline { 2 - 5 } & $\begin{array}{l}\mathrm{LiCl} \\
\mathrm{A}\end{array}$ & $\begin{array}{l}\mathrm{NaCl} \\
\mathrm{B}\end{array}$ & $\begin{array}{l}\mathrm{KCl} \\
\mathrm{C}\end{array}$ & $\begin{array}{l}\mathrm{CaF}_{2} \\
\mathrm{D}\end{array}$ \\
\hline 1 & 1 & 1 & 1 & 1 \\
\hline 2 & 1 & 1 & 2 & 2 \\
\hline 3 & 1 & 2 & 1 & 2 \\
\hline 4 & 1 & 2 & 2 & 1 \\
\hline 5 & 2 & 1 & 1 & 2 \\
\hline 6 & 2 & 1 & 2 & 1 \\
\hline 7 & 2 & 2 & 1 & 1 \\
\hline 8 & 2 & 2 & 2 & 2 \\
\hline
\end{tabular}

Table 11. Experimental Layout using $\mathrm{L}_{8}\left(2^{4}\right)$ Orthogonal Array

In this case, 1 represents the low level of the flux range values present in Table 1, whereas 2 represents the high level. Using the flux combinations in Table 11 to make five weld deposits for each flux combination which were subjected to tensile tests, the average ultimate tensile strength (UTS) test results for the eight flux combinations are shown in Table 12.

\begin{tabular}{|l|l|}
\hline Flux Number & $\begin{array}{l}\text { Average Ultimate Tensile Strength } \\
\text { (UTS) in MPa }\end{array}$ \\
\hline 1 & 247 \\
\hline 2 & 262 \\
\hline 3 & 268 \\
\hline 4 & 304 \\
\hline 5 & 298 \\
\hline 6 & 235 \\
\hline 7 & 304 \\
\hline 8 & 268 \\
\hline
\end{tabular}

Table 12. Experimental Results for the Ultimate Tensile Strength (UTS) Test

Since the UTS of these weld deposits fall within the values reported in other literature (Achebo \& Ibhadode, 2008), therefore the larger the UTS, the better the weld quality. The loss function of the larger the better quality characteristics is applied here as expressed in $\mathrm{Eq}(3)$. 


$$
L_{f}=\left(\frac{1}{n} \sum_{k=1}^{n} \frac{1}{y_{i}^{2}}\right)
$$

And the $\mathrm{S} / \mathrm{N}$ ratio, $\eta_{j}$ is

$$
\eta_{j}=-10 \log \mathrm{L}_{\mathrm{f}}
$$

The $\eta_{j}$ values for each UTS test result, $\mathrm{y}_{\mathrm{i}}$, in Table 12, were determined using Eqs (3) - (4) and the corresponding $\mathrm{S} / \mathrm{N}$ ratios there from are presented in Table 13

\begin{tabular}{|l|l|}
\hline Flux Number & S/N Ratio db \\
\hline 1 & 47.71 \\
\hline 2 & 48.37 \\
\hline 3 & 48.56 \\
\hline 4 & 49.66 \\
\hline 5 & 49.48 \\
\hline 6 & 47.42 \\
\hline 7 & 49.66 \\
\hline 8 & 48.56 \\
\hline
\end{tabular}

Table 13. S/N Ratios for the UTS Results

Categorizing the values in Table 13 into their various flux constituent elements and levels. Table 14 is created there from.

\begin{tabular}{|l|l|l|l|l|l|}
\hline Designation & Flux & \multicolumn{2}{|l|}{ S/N Ratio dB } & \multirow{2}{*}{$\begin{array}{l}\text { Total } \\
\text { mean }\end{array}$} & $\begin{array}{l}\text { Maximum - } \\
\text { Minimum }\end{array}$ \\
\cline { 3 - 4 } & $\begin{array}{l}\text { constituent } \\
\text { Elements }\end{array}$ & Level 1 & Level 2 & & \\
\hline $\mathrm{A}$ & $\mathrm{LiCl}$ & 48.57 & $48.78^{*}$ & \multirow{2}{*}{48.68} & 0.21 \\
\hline $\mathrm{B}$ & $\mathrm{NaCl}$ & 48.24 & $49.11^{*}$ & & 0.87 \\
\hline $\mathrm{C}$ & $\mathrm{KCl}$ & $48.85^{*}$ & 48.50 & & 0.35 \\
\hline $\mathrm{D}$ & $\mathrm{CaF}_{2}$ & 48.61 & $48.74^{*}$ & & 0.13 \\
\hline
\end{tabular}

* is the selected optimum level for the larger-the-better criterion

Table 14. Summary of S/N Ratios of different flux combinations.

From Table 14, the optimum flux composition is derived as $A_{2} B_{2} C_{1} D_{2}$. This composition is clearly specified as $30 \% \mathrm{LiCl}, 45 \% \mathrm{NaCl}, 30 \% \mathrm{KCl}$ and $10 \% \mathrm{CaF}_{2}$.These values combined is greater than $100 \%$ by weight. When the novel approach was applied, the composition was refined to $27 \% \mathrm{LiCl}, 37 \% \mathrm{NaCl}, 30 \% \mathrm{KCl}$ and $6 \% \mathrm{CaF}_{2}$.

In Table 14, a parameter with larger difference implies a high influence to weldability as its level is changed (Kim \& Lee, 2009). In this study, parameter B has the largest difference. The levels with these differences are shown in Fig. 1. Fig. 1 shows the S/N ratio graph where the dash line is the value of the total mean of the S/N ratio. Esme (2005) was of the opinion that percent contribution indicates the relative power of a factor to reduce variation. For a factor with a high percent contribution, a small variation will have a great influence on the performance. 


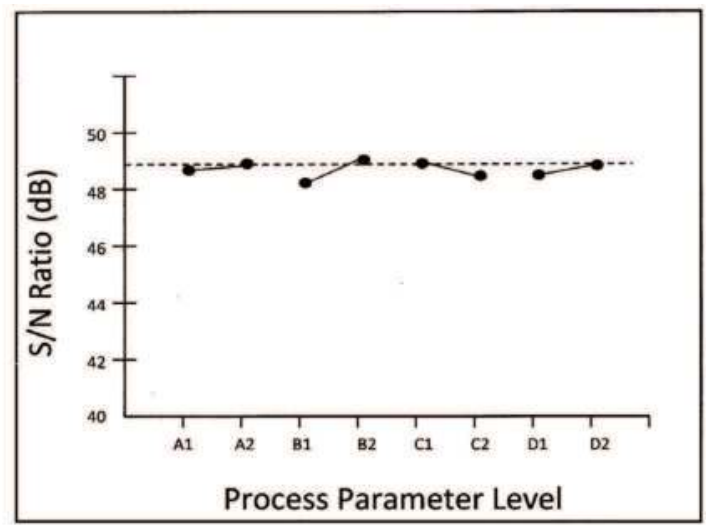

Fig. 1. S/N Ratio Graph

Table 15 shows the ANOVA results of the S/N Ratios in Table 14. Equations (5-7) were used to derive the sum of squares. Berginc et al (2006) proposed Eqs (5) and (6).

$$
\begin{gathered}
S S_{1}=\sum_{i=1}^{N} y_{i}^{2}-C F \\
C F=\frac{T_{s}^{2}}{N}
\end{gathered}
$$

Where

$\mathrm{T}_{\mathrm{S}}=$ the sum of all results

$\mathrm{N}=$ the number of results

$\mathrm{CF}=$ correction factor

Whereas, Scheaffer \& McClave (1982) proposed Eqs (7), which was used to determine the sum of squares for each of the flux elements.

$$
S S E=T S S-S S T=\sum_{i=1}^{N}\left(y_{i}-\bar{y}\right)^{2}
$$

\begin{tabular}{|l|l|l|l|l|l|l|}
\hline Parameter & $\begin{array}{l}\text { Process } \\
\text { Parameter }\end{array}$ & $\begin{array}{l}\text { Degree of } \\
\text { Freedom }\end{array}$ & $\begin{array}{l}\text { Sum of } \\
\text { Squares }\end{array}$ & Variance & F Ratio & $\begin{array}{l}\text { Contribution } \\
\text { Percentage }\end{array}$ \\
\hline A & $\mathrm{LiCl}$ & 1 & 0.02 & 0.02 & 0.01 & 0.38 \\
\hline $\mathrm{B}$ & $\mathrm{NaCl}$ & 1 & 0.35 & 0.35 & 0.22 & 6.72 \\
\hline $\mathrm{C}$ & $\mathrm{KCl}$ & 1 & 0.06 & 0.06 & 0.04 & 1.15 \\
\hline $\mathrm{D}$ & $\mathrm{CaF}$ & 1 & 0.01 & 0.01 & 0.01 & 0.19 \\
\hline Error & & 3 & 4.77 & 1.59 & - & 91.55 \\
\hline Total & & 7 & 5.21 & - & - & 100.00 \\
\hline
\end{tabular}

Table 15. ANOVA Results for the S/N Ratio containing Optimum Flux Combinations 
In Table 15, $\mathrm{NaCl}$ was found to be the major factor affecting Aluminum flux composition $(6.72 \%)$, followed by $\mathrm{KCl}(1.15 \%)$, whereas, $\mathrm{LiCl}$ and $\mathrm{CaF}_{2}$ have lower values of $0.38 \%$ and $0.19 \%$.

\subsection{Confirmation test}

The confirmation test is to validate the findings of this research work. The optimum formulation is used to make weld deposits that were subjected to the determination of the tensile property of the weldments. Here, the $\mathrm{S} / \mathrm{N}$ ratio is a powerful variable for measuring performance characteristics. It has to be predicted to verify the improvement of the performance characteristics.

The predicted $\mathrm{S} / \mathrm{N}$ ratio $\eta$ applying the optimal combination or levels is determined using $\mathrm{Eq}(8)$.

$$
\eta=\eta_{m}+\sum_{i=1}^{n}\left(\bar{\eta}-\eta_{m}\right)
$$

Where $\eta_{m}$ is the total mean of $\mathrm{S} / \mathrm{N}$ ratio, $\bar{\eta}$ is the mean of $\mathrm{S} / \mathrm{N}$ ratio at the optimal level, and $\mathrm{n}$ is the number of main welding parameters that significantly affect performance. The application of $\mathrm{Eq}(8)$ is illustrated as follows:

For $A_{2} B_{2} C_{1} D_{2}$

$$
\begin{aligned}
\text { For } \mathrm{A}_{2}: \bar{\eta}_{i}-\eta_{m}=48.78-48.68 & =0.10 \\
B_{2}: \bar{\eta}_{i}-\eta_{m}=49.11-48.68 & =0.43 \\
C_{1}: \bar{\eta}_{i}-\eta_{m}=48.85-48.68 & =0.17 \\
\mathrm{D}_{2}: \bar{\eta}_{i}-\eta_{m}=48.74-48.68 & =0.06 \\
& - \\
\sum_{i=1}^{n}\left(\bar{\eta}_{i}-\eta_{m}\right) & =0.76 \\
\eta=\eta_{\mathrm{m}}+\sum_{i=1}^{n}\left(\bar{\eta}_{\mathrm{i}}-\eta_{\mathrm{m}}\right)=48.68+0.76 & =49.44
\end{aligned}
$$

The existing flux combination used for welding processes has the formulation $A_{1} B_{1} C_{2} D_{1}$

$$
\begin{aligned}
& \text { For } \mathrm{A}_{1}: \bar{\eta}_{\mathrm{i}}-\eta_{\mathrm{m}}=48.57-48.68=-0.11 \\
& B_{1}: \bar{\eta}_{\mathrm{i}}-\eta_{\mathrm{m}}=48.24-48.68=-0.44 \\
& \mathrm{C}_{2}: \bar{\eta}_{\mathrm{i}}-\eta_{\mathrm{m}}=48.50-48.68=-0.18 \\
& \mathrm{D}_{1}: \bar{\eta}_{\mathrm{i}}-\eta_{\mathrm{m}}=48.61-48.68=-0.07 \\
& \overline{-0.80} \\
& \eta=\eta_{\mathrm{m}}+\sum_{i=1}^{n}\left(\bar{\eta}_{\mathrm{i}}-\eta_{\mathrm{m}}\right)=48.68-0.80=47.88
\end{aligned}
$$


The same procedure was carried out for $A_{2} B_{2} C_{1} D_{2}$ produced from experimental methods. The increase in $\mathrm{S} / \mathrm{N}$ ratio shows that there are greater amounts of the same alloying elements in the weld chemical composition than that contained in the weld deposit made by the predicted process parameter. Its predicted $\mathrm{S} / \mathrm{N}$ ratio is also presented in Table 16.

The results of experimental confirmation using optimal welding parameters and comparing it with predicted process are shown in Table 16.

\begin{tabular}{|c|c|c|c|c|}
\hline \multirow[t]{2}{*}{$\begin{array}{l}\text { Process } \\
\text { Factors }\end{array}$} & \multirow[t]{2}{*}{$\begin{array}{l}\text { Initial Process } \\
\text { Parameter }\end{array}$} & \multicolumn{2}{|c|}{$\begin{array}{l}\text { Optimum Process } \\
\text { Parameters }\end{array}$} & \multirow[t]{2}{*}{$\begin{array}{l}\text { Inprovement } \\
\text { In S/N Ratio }\end{array}$} \\
\hline & & Prediction & Experiment & \\
\hline Flux Composition & $\mathrm{A}_{1} \mathrm{~B}_{1} \mathrm{C}_{2} \mathrm{D}_{1}$ & $\mathrm{~A}_{2} \mathrm{~B}_{2} \mathrm{C}_{1} \mathrm{D}_{2}$ & $\mathrm{~A}_{2} \mathrm{~B}_{2} \mathrm{C}_{1} \mathrm{D}_{2}$ & \multirow[t]{3}{*}{1.62} \\
\hline UTS (MPa) & 296 & 316 & 320 & \\
\hline $\mathrm{S} / \mathrm{N} \mathrm{dB}$ & 47.88 & 49.44 & 49.50 & \\
\hline
\end{tabular}

Table 16. Confirmation Experimental Test Results

The improvement in $\mathrm{S} / \mathrm{N}$ ratio from the initial welding parameter to the optimal welding parameter is $1.62 \mathrm{~dB}$ and the UTS increased by 1.08 times. Therefore the UTS is significantly improved by using the Taguchi method.

\section{Expert evaluation method}

The expert evaluation method was applied by Nikitina (2004) and further applied by Achebo (2009) for developing new flux compositions based on the shear stress of the weld metal. Using this method, Experts in the field of welding were used; five Engineers who are welders, each with at least 15 years working experience; three independent welders with at least 25 years welding experience; and two University Professors of Manufacturing Engineering with exceptional welding experience for over 10 years. These were employed to evaluate the technological performance of the newly developed fluxes. The combined skill of the experts was taken into consideration by the coefficient $\delta$ equal to 2 and 1 which is a 10 point scale, where 2 represents the weld of highest quality and 1 represents the weld with the lowest quality (Nikitina (2004); Achebo (2009)). In this study, the Expert evaluation method is used to develop new welding fluxes as illustrated in Tables (17 - 20).

In order, to implement this expert evaluation method, it demands that Table 1 be rearranged, and this in turn produced Table 17.

\begin{tabular}{|l|l|l|l|l|l|}
\hline \multirow{2}{*}{} & \multirow{2}{*}{ Factor } & \multicolumn{3}{|c|}{ Variation Level } & \multirow{2}{*}{ Variation Range } \\
\cline { 3 - 5 } & & Main & Lower & Upper & \\
\hline $\mathrm{X}_{1}$ & $\mathrm{LiCl}$ & 27.5 & 25 & 30 & 2.5 \\
\hline $\mathrm{X}_{2}$ & $\mathrm{NaCl}$ & 37.5 & 30 & 45 & 7.5 \\
\hline $\mathrm{X}_{3}$ & $\mathrm{KCl}$ & 35 & 30 & 40 & 5 \\
\hline $\mathrm{X}_{4}$ & $\mathrm{CaF}_{2}$ & 7.5 & 5 & 10 & 2.5 \\
\hline
\end{tabular}

Table 17. Chemical Composition arrangement of Aluminum welding flux elements

Using the derived flux composition in Table 7 the expert evaluation scores based on the scale of $1-10$ were itemized and this lead to the generation of Table 18. 


\begin{tabular}{|l|l|}
\hline $\begin{array}{l}\text { Flux } \\
\text { No }\end{array}$ & $\begin{array}{l}\text { Average Evaluation } \\
\text { scores of Experts }\end{array}$ \\
\hline 1 & 5.8 \\
\hline 2 & 6.8 \\
\hline 3 & 4.6 \\
\hline 4 & 6 \\
\hline 5 & 8.4 \\
\hline 6 & 6.8 \\
\hline 7 & 4.6 \\
\hline 8 & 5.2 \\
\hline
\end{tabular}

Table 18. Expert Evaluation of Flux Composition constituent Elements

The experts were asked to make the individual assessments of the performance and characteristics of the Eight flux compositions based on their UTS, with their average values listed in Table 8. Table 19 shows the Expert evaluation of the quality of the flux weldments based on UTS.

\begin{tabular}{|c|c|c|c|c|c|c|c|c|c|c|}
\hline \multirow{2}{*}{$\begin{array}{l}\text { Number } \\
\text { of Experts }\end{array}$} & \multicolumn{8}{|c|}{ Scores made by Experts } & \multirow[t]{2}{*}{$\mathrm{T}_{\mathrm{i}}$} & \multirow[t]{2}{*}{$\delta_{i}$} \\
\hline & 1 & 2 & 3 & 4 & 5 & 6 & 7 & 8 & & \\
\hline 1 & 5 & 8 & 4 & 5 & 9 & 5 & 3 & 4 & 5 & 1.4 \\
\hline 2 & 7 & 7 & 5 & 8 & 8 & 8 & 4 & 2 & 5 & 1.7 \\
\hline 3 & 4 & 5 & 4 & 7 & 8 & 6 & 6 & 4 & 5 & 1.2 \\
\hline 4 & 6 & 6 & 4 & 4 & 8 & 7 & 5 & 5 & 6 & 1.5 \\
\hline 5 & 7 & 8 & 6 & 6 & 9 & 8 & 5 & 6 & 5 & 2 \\
\hline$\sum_{i=1}^{n} x_{i j} \delta_{j}$ & 46.7 & 54.1 & 36.9 & 47.0 & 65.8 & 54.3 & 35.0 & 33.3 & {$\left[\sum_{i=1}^{n} x_{i j} \delta_{i}\right]$} & $\begin{array}{l}\quad=46.64 \\
\text { Average }\end{array}$ \\
\hline $\mathrm{R}$ & 4 & 6 & 3 & 5 & 8 & 7 & 2 & 1 & & \\
\hline$r$ & 0.06 & 7.46 & 9.74 & 0.36 & 19.16 & 7.66 & 1.64 & 13.34 & & \\
\hline \multirow[t]{2}{*}{$r_{j}^{2}$} & $3.60 \times 10^{-3}$ & 55.65 & 94.88 & 0.13 & 367.11 & 58.68 & 135.49 & 177.96 & \multicolumn{2}{|c|}{$\sum r_{j}^{2}=889.90$} \\
\hline & 5.8 & 6.8 & 4.6 & 6.0 & 8.4 & 6.8 & 4.6 & 5.2 & & \\
\hline
\end{tabular}

Table 19. Expert Evaluation of the Quality of the flux weldments based on UTS

To evaluate the extent of the correlation between the scores and the individual expert assessments, the rank correlation coefficient (concordation) was applied.

$$
W=\frac{12 m \sum_{i=1}^{n} r_{i}^{2}}{\left[m\left(n^{3}-n\right)-\sum_{i=1}^{m} T_{i}^{2}\right]\left(\sum_{i=1}^{m} \delta_{i}\right)^{2}}
$$


Where

$$
\begin{gathered}
\sum_{j=1}^{n} r^{2}=\sum_{j=1}^{n}\left[\sum_{i=1}^{m} a_{i j} \delta_{i}-\frac{\sum_{j=1}^{n} \sum_{i=1}^{n} x_{i j} \delta_{i}}{n}\right]^{2} \\
T_{i}=\left(\sum t_{i}\right)
\end{gathered}
$$

And $t_{i}=$ number of repetitions of each score in the ith series, $n$ is the number of flux compositions, $\mathrm{m}$ is the number of experts.

Substituting the corresponding values into $\mathrm{Eq}(9)$, gives

$$
W=\frac{12 \times 5 \times 889.90}{\left[5\left(8^{3}-8\right)-26^{2}\right](7.8)^{2}}=0.48
$$

The significance of the concordation coefficient was calculated using the criterion equation in $\mathrm{Eq}(11)$

$$
\begin{gathered}
x_{\text {cal }}^{2}=m(n-1) W \\
x_{\text {cal }}^{2}=5(8-1) 0.48=16.8
\end{gathered}
$$

Since the tabulated volume $\chi_{\text {table }}^{2}(0.05,7)=14.1$, which is lower than the calculated value, it is concluded that the expert evaluation scores are in agreement.

Multiple regression analysis in the excel Microsoft package was used to analysis the flux composition, elements in Table 7 and the independent variable, $\mathrm{y}_{\mathrm{i}}$ which is the average scores of the expert evaluation process shown in Table 18, to be as follows:

$$
y=6.54-0.035 \bar{\beta}+0.007 \beta+0.000 \beta+0.041 \beta
$$

This regression analysis can also be derived manually from the least square method which suggests that

$$
\bar{y}=\underset{1}{\bar{\beta}}+\underset{\beta}{\bar{\beta}} x_{1}+\underset{2}{\bar{\beta}} x_{2}+\underset{3}{\bar{\beta}} x_{3}+\underset{4}{\beta} x_{4}
$$

And the sum of square error, SSE is represented by

$$
S S E=\sum_{i=1}^{n}\left(y_{i}-\bar{y}\right)^{2}
$$

Where $\beta_{i}$ is the independent variables representing the flux constituent elements $\mathrm{i}=1,2,3$ and 4 Substituting $\mathrm{Eq}(13)$ into $\mathrm{Eq}(14)$ 


$$
S S E=\left(y_{i}-\underset{0}{\bar{\beta}}-\bar{\beta} x_{1}-{ }_{2} x_{2}-\underset{3}{\bar{\beta}} x_{3}-\bar{\beta} x_{4}\right)^{2}
$$

Differentiating Eq (15) with respect to $\overline{\beta_{1}}$, the following is obtained

$$
\frac{\partial(S S E)}{\partial \bar{\beta}}=-2 \sum_{i=1}^{n} x_{1}\left(y_{i}-\underset{0}{\bar{\beta}}-\bar{\beta} x_{1}-\underset{2}{\bar{\beta}} x_{2}-\underset{3}{\bar{\beta}} x_{3}-\bar{\beta} x_{4}\right)=0
$$

Differential analysis were also done for

$$
\frac{\partial(S S E)}{\partial \bar{\beta}}, \frac{\partial(S S E)}{\partial \bar{\beta}} \text { and } \frac{\partial(S S E)}{\partial \bar{\beta}}
$$

And values for $\bar{\beta}_{1},{ }_{2},{ }_{3}$ and $\bar{\beta}$ were arranged in a matrix form. Quadratic equations were formed from the matrix layout. This enabled the determination of the independent variables

\begin{tabular}{|c|c|c|c|c|}
\hline Factor & $\overline{\beta_{1}}$ & $\overline{\beta_{2}}$ & $\overline{\beta_{3}}$ & $\overline{\beta_{4}}$ \\
\hline$k_{i}$ & -0.04 & 0.01 & 0.00 & 0.04 \\
\hline$l_{j}$ & 2.50 & 7.50 & 5.00 & 2,50 \\
\hline$k_{i} l_{j}$ & -0.09 & 0.08 & 0.00 & 0.10 \\
\hline \multicolumn{5}{|l|}{ Composition by wt } \\
\hline Step & -0.03 & 0.03 & - & 0.03 \\
\hline \multirow[t]{8}{*}{ Zero level } & 27.50 & 37.50 & 35.00 & 7.50 \\
\hline & 27.47 & 37.53 & 35.00 & 7.53 \\
\hline & 27.44 & 37.56 & 35.00 & 7.56 \\
\hline & 27.41 & 37.59 & 35.00 & 7.59 \\
\hline & $:$ & $:$ & $:$ & $:$ \\
\hline & $:$ & $:$ & $:$ & $:$ \\
\hline & $:$ & $:$ & $:$ & $:$ \\
\hline & 25.00 & 40.02 & 35.00 & 10.01 \\
\hline
\end{tabular}
which lead to the generation of $\mathrm{Eq}(12)$.

This model lead to the development of new flux compositions as shown in Table 20

Table 20. Flux Development Process

After this tedious process, 74 new flux compositions emerged. The best combination of the lot, and the one which had the optimum combination was the one with the following element proportion of $28.2 \% \mathrm{~L}_{\mathrm{i}} \mathrm{Cl}, 38.6 \% \mathrm{NaCl}, 35 \% \mathrm{KCl}$ and $8.6 \% \mathrm{CaF}_{2}$. This conclusion was arrived at on the basis of possessing the highest UTS of $298 \mathrm{MPa}$ amongst the lot. This flux composition was over a $100 \%$ by weight. Therefore the flux composition was then further subjected to a novel approach elucidated above in the Hadamard Matrix Method. A new flux composition of $25.4 \% \mathrm{LiCl}, 35 \% \mathrm{NaCl}, 33 \% \mathrm{KCl}$ and $6.6 \% \mathrm{CaF}_{2}$ was generated with an impressive UTS of $308 \mathrm{MPa}$. 


\section{Discussion of results}

Three methods for developing flux combinations and compositions were investigated. These were the Hadamard Multivariate Chemical Composition Model, the Taguchi Method, and the Expert Evaluation Method. From the findings, the Hadamard Multivariate model was capable of generating several flux compositions and integrating the effects of one variable on another variable (the interactions), in the process of determining the optimum composition. Using this method the optimum composition was determined to be $30 \% \mathrm{~L}$ $45 \% \mathrm{NaCl}, 30 \% \mathrm{KCl}$ and $5 \% \mathrm{CaF}_{2}$. This composition value is above $100 \%$. However, applying the novel approach elucidated above will lead to a rearrangement of the percentages of the flux elements of the new composition, being the following: $27.5 \% \mathrm{~L}_{\mathrm{i}} \mathrm{Cl}$, $37.5 \% \mathrm{NaCl}, 30 \% \mathrm{KCl}$ and $8.5 \% \mathrm{CaF}_{2}$. However from the several compositions generated applying this novel method, this new flux composition gave the highest value of UTS of 316 $\mathrm{MPa}$ which is within the range of reported values in other literature (Achebo and Ibhadode, 2008).

The Taguchi method was also applied to determine the optimum flux composition, which gave a composition of $30 \% \mathrm{~L}_{\mathrm{i}} \mathrm{Cl}, 45 \% \mathrm{NaCl}, 30 \% \mathrm{KCl}$ and $10 \% \mathrm{CaF}_{2}$, but having applied this novel method, a composition of $27 \% \mathrm{~L}_{\mathrm{i}} \mathrm{Cl}, 37 \% \mathrm{NaCl}, 30 \% \mathrm{KCl}$ and $6 \% \mathrm{CaF}_{2}$ was derived. The derived flux composition weld deposit gave an UTS of $320 \mathrm{MPa}$.

Further investigation was done using the Expert evaluation method. In this case, the expert evaluation skills based on the performance of the flux compositions generated by other optimization methods were used to further generate new flux compositions. The generated flux composition using this method was $28.2 \% \mathrm{~L}_{\mathrm{i}} \mathrm{Cl}, 38.6 \% \mathrm{NaCl}, 35 \% \mathrm{KCl}$ and $8.6 \% \mathrm{CaF}_{2}$, with the application of the above stated novel method, the composition that emerged was $25.4 \% \mathrm{~L}_{\mathrm{i}} \mathrm{Cl}, 35 \% \mathrm{NaCl}, 33 \% \mathrm{KCl}$ and $6.6 \% \mathrm{CaF}_{2}$ with an UTS of $308 \mathrm{MPa}$.

Having considered the optimum compositions above, the flux compositions formulated and used by other researchers were investigated. Varley (1970) in his book suggested a typical flux composition for Aluminum welding as $30 \% \mathrm{NaCl}, 28 \% \mathrm{KCl}, 26 \% \mathrm{~L}_{\mathrm{i}} \mathrm{Cl}$ and $16 \% \mathrm{NaF}$, Glizmaneko \& Yevseyer gave some values for Aluminum flux composition in the range of $19-45 \% \mathrm{NaCl}, 29-51 \% \mathrm{KCl}, 9-15 \% \mathrm{~L}_{\mathrm{i}} \mathrm{Cl}$ and $7-10 \% \mathrm{NaF}$. Davies (1984) gave the range of $0-30 \% \mathrm{~L}_{\mathrm{i}} \mathrm{Cl}, 0.6 \% \mathrm{KCl}, \mathrm{NaCl}$-the remainder and $5-15 \% \mathrm{KF}$. Manfredi et al (1997) gave a flux composition of $70 \% \mathrm{NaCl}, 28 \% \mathrm{KCl}$ and $2 \% \mathrm{CaF}_{2}$, whereas Utigard et al (1998) used a flux composition of $47.5 \% \mathrm{NaCl}, 47.5 \% \mathrm{KCl}$ and $5 \%$ Fluoride salts. Other investigators who did the tensile test of their Aluminum fluxed weld metals, had the UTS test results in the range of 298 - 434MPa (Shah, et al (1992); Ellis (1996)). Padmanabham et al (2007) had a UTS test result of a range of 255 - 334MPa and Achebo \& Ibhadode (2008) had a weld metal whose UTS was 310MPa. Weston investigated the weldments of Aluminum alloys 2219 and 5083 and found their UTS to be 270MPa and 297MPa respectively. Yoon (1996) also investigated the tensile properties of Aluminum alloy 6061 and found its UTS to be 200MPa. Palmer et al (2006) investigated the tensile properties of Aluminum alloy 6061-T6 and found its UTS to be 310MPa while their investigation on 6061-0 alloy showed a corresponding value of $117 \mathrm{MPa}$.

From the values above, it can be seen that the optimum flux composition constituent elements derived by applying the Hadamard Matrix design method, Taguchi optimization method and the Expert evaluation method fall within the range of values formulated by other investigators. The same applies to their UTS values. This therefore confirms that the three methods considered in this study are very effective and are recommended for application depending on any researcher's needs. 


\section{Conclusion}

In this study, several processes for the selection of flux composition elements in their various proportions, have been demonstrated. Three optimization methods were used to generate new flux compositions. A novel approach was applied to round off the sum of the percentage by weight of the flux constituent elements to $100 \%$. The Hadamard multivariate method and the Taguchi method were less complex and easier to apply. These two methods developed optimum flux compositions which eventually gave the highest UTS values within their various groups. The difference between these two methods however, is that the Hadamard method actually considers the interactions between the elements that constitute the composition. However, very many flux compositions, with rather wide ranging differences tend to be produced, these would usually require a significant number of weld tests over a rather long period of time for the researcher to narrow the entire process down to an optimum flux. The Taguchi method is also very adaptable and maneuverable in terms of how diverse constituent elements could be researched simultaneously. The drawback however is that the Taguchi method has received scathing criticism and is not a well trusted method in certain quarters in general. It is best to apply the Taguchi method in consonance with another method to improve its credibility. The expert evaluation method, on the other hand, has the advantage that it does not generate initial flux compositions. It utilizes the assessments made by experts who have had considerable work experience in the field of welding and with good academic background. These assessments were used to generate new flux compositions whose welds were subjected to tensile tests to determine their UTS. This property was seen as a measure of performance, in terms of weld quality, ductility, strength and weldability. It was observed however that the expert evaluation method seems to be very cumbersome. It is also prone to the inevitability of human error. However when it is applied in certain cases which lean towards real quality control and marketing, it is the most ideal. Conclusively, a multiphysical approach in applying these methods has been successfully demonstrated to generate an optimum flux composition; and the relevance of the use of any of these methods, or a combination of the three, would depend on the aim of the research the investigators intend to carry out.

\section{References}

Achebo J.I \& Ibhadode, A.O.A. (2008), Development of a New Flux for Aluminum Gas Welding; Advanced Material Research, Vols. 44/46 (Trans Tech Publications, Switzerland). p.677-684.

Achebo J.I. (2009), Development of Compositions of Aluminum Welding Fluxes, using Statistical Method. International Multi conference of Engineeers and Computer Scientists, Hong Kong, 18-20 March, p.1876.

Achebo J.I \& Ibhadode, A.O.A. (2009), Determination of Optimum Welding Flux Composition Using the Bend Strength Test Technique; Advanced Material Research, Vols. 62/64 (Trans Tech Publications, Switzerland). p.393-397.

Antony, J \& Antony, F. J. (2001) Teaching the Taguchi Method to Industrial Engineers, Work Study, MCB University Press, Vol. 50, No. 4, p.141- 149 (ISSN 0043-8022).

Berginc, B; Kampus, Z \& Sustarsic, B. (2006) The Use of Taguchi Approach to Determine the Influence of Injection Moulding Parameters on the Properties of Green Parts, 
Journal of Achievements in Materials and Manufacturing Engineering, vol. 15, Issue 1 2, p.66.

Boniszewski T (1979) Manual Metal Arc Welding. Metallurgist and Materials Technologist, Vol.11 No.10. p.567-574; Vol.11. No.11. p.640-644; Vol. 11. No.12. p.697-705

Chai, C.S. \& Eagar, T.W.(1983) Prediction of weld-metal composition during flux-shielded welding, Journal of Materials for Energy Systems. American Society for Metals, Vol. 5, No. 3, December, p.160-164

Davies, A.C. (1984) Welding Science, Prentice Hall publication, UK. p.55

Diamond, W. J. (1989) Practical Experimental Design for Engineers and Scientists, 2nd Ed. Van Nostrand Reinhold, New York, p.89 - 123, 296 - 306.

Ellis, M.B.D (1996). Fusion Welding of Aluminum Lithium Alloys Welding \& Metal Fabrication, Vol. 2. p.55-60.

Esme, U. (2009) Application of Taguchi Method for the Optimization of Resistance Spot Welding Process, The Arabian Journal for Science and Engineering, Vol. 34, No. 2B, p.519 - 528

Glizmaneko, D. \& Yevseyer, G. (undated) Gas Welding and Cutting, Peace Publishers, Moscow, p.180

Holderness, A. \& Lambert, J. (1982) A New Certificate Chemistry. $6^{\text {th }}$ Edition, Heinemann Publishers, Ibadan,

Jackson, C.E. (1973) ‘Fluxes and Slags in Welding' Welding Research Council Bulletins No.190, p.25-57.

Kim H. R. \& Lee, K. Y.(2009) Application of Taguchi Method to Hybrid Welding Conditions of Aluminum Alloy, Journal of Scientific \& Industrial Research, Vol. 68, p.296 - 300

Manfredi, O; Wulh, W. \& Bohlinger, I. (1997) 'Characterizing the Physical and Chemical Properties of Aluminum Dross' JOM, November, p.48

Natalie, C. A.; Olson, D. L. \& Blander, M. (1986) 'Physical and Chemical Behaviour of Welding Fluxes' Annual Review of Materials Science, Vol.16, p.389 - 413, August

Nikitina, E. V. (2004) 'Development of the Composition of Electrode Coatings for Welding Aluminum Alloys Using the Expert Evaluation Method', Welding International, Vol. 18(4), 307 - 310.

Padmanabham, G; Schaper, M; Pandey, S. \& Simmchen, E (2007)'Tensile and Fracture Behavior of Pulsed Gas Metal Arc Welded Al - Cu - Li' Welding Journal, Vol. 86, No. 6, p.147-s - 160-s, June

Palmer, T. A; Elmer, J. W; Brasher, D; Butler, D. \& Riddle, R. (2006) Development of an Explosive Welding Process for Producing High - Strength Welds between Niobium and 6061-T651 Aluminum' Welding Journal, Vol. 85, No.11, p.252-s - 263-s,

Scheaffer, R. L. \& McClave, J. T. (1982) Statistics for Engineers, Duxbury Press, Boston, p.239 355.

Shad, S.R. Wittig, J.E., \& Hahn, G.T.(1992) Microstructural Analysis of a High Strength Al$\mathrm{Cu}-\mathrm{Li}$ (Weldalite 049).Alloy Weld. Proceedings of the $3^{\text {rd }}$ International Conference on Trends in Welding Research, Gatlinburg, Tenn. .

The James F. Lincoln Arc Welding Foundation; Weld Cracking:An Excerpt from Fabricators' and Erectors'Guide to Welded Steel Construction; Information available on http://www.treatrade.hr/pdf/DM/weldcracking.pdf

Utigard, T. A.; Friesen, K,; Roy, R. R.; Lim, J.; Silny, A. \& Dupuis, C. (1998) ‘The Properties and Uses of Fluxes in Molten Aluminum Processing' JOM, November, p.38 
Varley, P.C. (1970) The Technology of Aluminum and its Alloys: Newnes- Butterworths, London p.78

Weston, J. (2001) Laser Welding of Aluminum Alloys. PhD Thesis, Department of Materials Science and Metallurgy, University of Cambridge, p.142

Yoon, J. W. (1996) Laser Welding of Aluminum Alloys. , Department of Materials Science and Metallurgy, University of Cambridge 


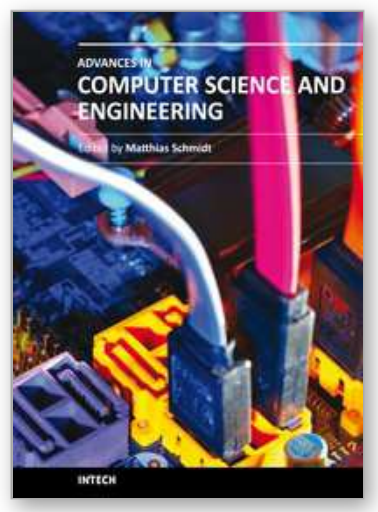

\author{
Advances in Computer Science and Engineering \\ Edited by Dr. Matthias Schmidt
}

ISBN 978-953-307-173-2

Hard cover, 462 pages

Publisher InTech

Published online 22, March, 2011

Published in print edition March, 2011

The book Advances in Computer Science and Engineering constitutes the revised selection of 23 chapters written by scientists and researchers from all over the world. The chapters cover topics in the scientific fields of Applied Computing Techniques, Innovations in Mechanical Engineering, Electrical Engineering and Applications and Advances in Applied Modeling.

\title{
How to reference
}

In order to correctly reference this scholarly work, feel free to copy and paste the following:

Joseph I. Achebo (2011). A Multiphysics Analysis of Aluminum Welding Flux Composition Optimization Methods, Advances in Computer Science and Engineering, Dr. Matthias Schmidt (Ed.), ISBN: 978-953-307173-2, InTech, Available from: http://www.intechopen.com/books/advances-in-computer-science-andengineering/a-multiphysics-analysis-of-aluminum-welding-flux-composition-optimization-methods

\section{INTECH}

open science | open minds

\author{
InTech Europe \\ University Campus STeP Ri \\ Slavka Krautzeka 83/A \\ 51000 Rijeka, Croatia \\ Phone: +385 (51) 770447 \\ Fax: +385 (51) 686166 \\ www.intechopen.com
}

\author{
InTech China \\ Unit 405, Office Block, Hotel Equatorial Shanghai \\ No.65, Yan An Road (West), Shanghai, 200040, China \\ 中国上海市延安西路65号上海国际贵都大饭店办公楼 405 单元 \\ Phone: +86-21-62489820 \\ Fax: $+86-21-62489821$
}


(C) 2011 The Author(s). Licensee IntechOpen. This chapter is distributed under the terms of the Creative Commons Attribution-NonCommercialShareAlike-3.0 License, which permits use, distribution and reproduction for non-commercial purposes, provided the original is properly cited and derivative works building on this content are distributed under the same license. 